\title{
A Rare Case of Hepatic T-Cell Rich B-Cell Lymphoma (TCRBCL) in a Juvenile Dog
}

\author{
Tae-Ho CHUNG ${ }^{1}$, Catherine $\mathrm{LAMM}^{2}$, Young-Chul CHOI ${ }^{3)}$, Jung-Woo LEE'), Dohyeon YU ${ }^{4)}$ and Ul-Soo CHOI ${ }^{5) *}$ \\ 1) Department of Animal Science, Joongbu University, Gumsan-gun, Chungnam 312-702, South Korea \\ 2) IDEXX Laboratories, 2825 KOVR Drive, West Sacramento, CA 95605, U.S.A. \\ 3) Africa Animal Medical Center, Gangseo-gu, Seoul 678-709, South Korea \\ 4) Department of Veterinary Clinical Pathology, Chonnam National University, Gwangju 500-757, South Korea \\ ${ }^{5)}$ Department of Veterinary Clinical Pathology, Chonbuk National University, Jeonju-si, Jeollabuk-do 561-756, South Korea
}

(Received 9 February 2014/Accepted 5 June 2014/Published online in J-STAGE 3 October 2014)

\begin{abstract}
A 7-month-old castrated male French Bull dog was presented with vomiting, lethargy, anorexia and weight loss of 2 weeks duration. The patient's history and clinical manifestations of suspected hepatopathy were subjected to ultrasonography, radiography, biochemical investigations and cytology of hepatic lesion. The cytologic impression was hepatic lymphoma, which was later confirmed by histopathology. The neoplastic cells were strongly diffusely immunoreactive for PAX5, but not immunoreactive for CD3, and B lymphocyte specific clonal proliferation was detected using by assay of antigen receptor rearrangement. Large numbers of immunoreactive mature nonneoplastic lymphocytes were admixed with the neoplastic cell population. Therefore, the immunohistochemical results were definitively consistent with a T-cell rich B-cell lymphoma (TCRBCL). This is the first description of a hepatic TCRBCL in a juvenile dog showing a poor response to aggressive chemotherapy.

KEY WORDS: diffuse large B-cell lymphoma, hepatopathy, juvenile dog, lymphoma, T-cell rich B-cell lymphoma
\end{abstract}

doi: 10.1292/jvms.14-0088; J. Vet. Med. Sci. 76(10): 1393-1397, 2014

Lymphoma is a malignant disorder derived from clonal proliferation of lymphoid precursor cells and is one of the most commonly diagnosed canine neoplasms [5]. Tumor cell type is an important criterion for treatment and prognosis, and lymphoma has been broadly divided into two major groups of B-cell tumors and T-cell tumors based on the immunophenotype of the neoplastic cells [13]. Hepatosplenic T-cell lymphoma is characterized by infiltration of the liver, spleen and bone marrow with neoplastic lymphocytes, absence of peripheral lymphadenopathy and an aggressive clinical course, but no case reports have described hepatic T-cell rich B-cell lymphoma (TCRBCL) in veterinary practice [6]. In addition, canine lymphoma is diagnosed predominantly in middle-aged dogs with a median of 5-9 years [5]. No reports have described hepatic T-cell rich B-cell lymphoma in a juvenile dog. This report details the case of a 6-month-old French Bull dog as the first juvenile case of hepatic T-cell rich B-cell lymphoma.

A 7-month-old castrated male French Bull dog presented with vomiting, lethargy, anorexia and weight loss of 2 weeks duration. A complete blood count was within normal physiological reference ranges, except for mild anemia without polychromasia in the blood smear (red blood cells, $4.95 \times 10^{6} / \mu l$; reference range, $5.50-8.50 \times 10^{6} / \mu l$ ). Serum biochemistry revealed mildly decreased electrolytes and

*Correspondence to: Choi, U.-S., Department of Veterinary Clinical Pathology, Chonbuk National University, Jeonju-si, Jeollabukdo 561-756, South Korea. e-mail: uschoi@jbnu.ac.kr

(C)2014 The Japanese Society of Veterinary Science

This is an open-access article distributed under the terms of the Creative Commons Attribution Non-Commercial No Derivatives (by-nc-nd) License $<$ http://creativecommons.org/licenses/by-nc-nd/3.0/>. increased liver enzyme activity, which were consistent with hepatic insufficiency. Survey radiography identified severe hepatomegaly, blunted liver margin and serosal detail loss. On ultrasonographic examination, hepatic echogenicity was homogenously increased compared with splenic and renal echogenicities, and there were no findings of focal abnormalities. However, it was difficult to make comparison with echogenicity between spleen and liver, and spleen was enlarged and hypoechoic (Fig. 1a and 1b). Liver was ultrasound-guided aspirated, smeared and stained with Wright-Giemsa stain for cytological interpretation.

The cytological specimens contained moderately cellular smears consisting of a moderately increased number of immature lymphocytes and a low number of small lymphocytes (70\% and $30 \%$, respectively) and clusters of hepatocytes with increased cytoplasmic basophilia (Fig. 2). More than half the cells were disrupted and scattered in the background with a large amount of cellular debris. Immature lymphocytes were medium to large with scant to mild amounts of deeply basophilic cytoplasm and occasional small vacuoles. Nuclei were round to indented to irregularly contoured with coarsely clumped chromatin and no prominent nucleoli. Numerous variably sized basophilic cytoplasmic fragments were also noted in the background. The cytological impression was lymphoma, possibly of liver origin, which was also highly suspected in conjunction with the patient's history, clinical manifestations of suspected hepatopathy and ultrasonography findings.

A surgical biopsy for histology and immunophenotyping was recommended for a definitive diagnosis. After conducting the liver biopsy, the tissues were fixed in $10 \%$ bufferedformalin and sent to IDEXX Laboratories (Westbrook, ME, U.S.A.) for histology and immunohistochemistry. The 


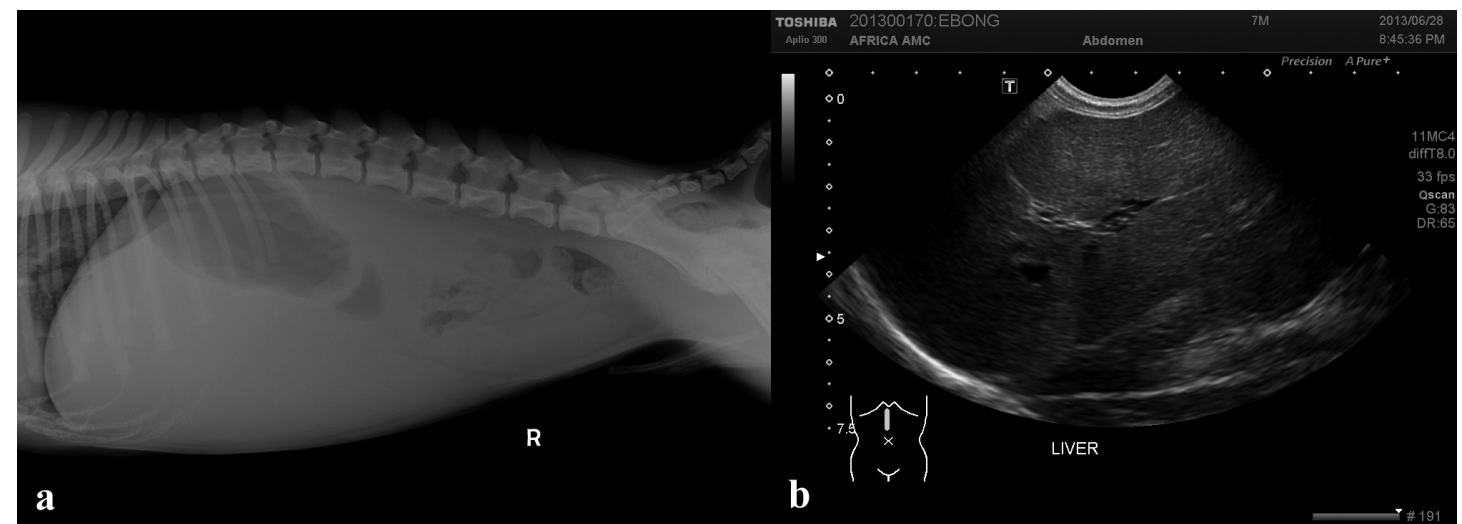

Fig. 1. On abdominal radiograph, there is extremely hepatomegaly with blunt margination and caudal deviation of gastric axis. There is poor detail in the peritoneal space, and the animal is in thin body condition (a). Uniformly increased hepatic parenchymal echogenicity, reduced visualization of portal structures and small amount of ascites are described. There is extension of the liver ventral to the stomach, and liver is slightly higher echo intensity than the spleen (b).

paraffin samples were sectioned at $5 \mu \mathrm{m}$ and stained with hematoxylin and eosin for clinical histology. The avidinbiotin complex (ABC) method was applied for immunohistochemistry. Antigen retrieval was performed by placing the slides in a bath of $10 \mathrm{mM}$ citric acid $(\mathrm{pH} \mathrm{6)}$ ) and boiling for $16 \mathrm{~min}$ in an autoclave. Mouse anti-canine CD3 (clone CA17.2A12, Serotec, Oxford, U.K.) and mouse anti-human PAX5 (clone BC/24, Biocare Medical, Walnut Creek, CA, U.S.A.) primary antibodies were used. Histologically, there were sheets of neoplastic round cells markedly expanding in the portal regions that formed numerous clusters within the adjacent hepatic parenchyma. The neoplastic cells were large (25-30 $\mu \mathrm{m}$ in diameter) with a moderate amount of eosinophilic cytoplasm and indistinct cell borders. The nuclei were extremely large with finely stippled to vesicular chromatin and occasionally contained 1-2 prominent nucleoli (Fig. 3). Marked anisocytosis and anisokaryosis existed. Occasional multinucleate cells were found, and small numbers of mature lymphocytes were multifocally admixed with the neoplastic cell population. Rare pigment-laden macrophages were present, and intervening hepatocytes were diffusely and markedly swollen with abundant indistinct clear cytoplasmic vacuoles. Marked hepatocellular pleomorphism was also detected.

PAX5 and CD79 are both B cell markers. PAX5 is a "cleaner" IHC with less non-specific staining and is preferred by most anatomic pathologists [8]. Most B cell lymphomas are immunoreactive for both; although a small proportion is positive for PAX5 and not CD79 and vice versa. So, if there is a lymphoma that is negative for CD3 (not T cell) and negative for PAX5, veterinary pathologists would run a CD79 before calling it a "null cell". We used a dual stain (CD3/ PAX5 on the same slide), and our specific protocol is briefly described as follow. Dilution ratio was 1:300 using Renoir Red diluent (Biocare Medical, Walnut Creek, CA, U.S.A.). Incubation time was $60 \mathrm{~min}$, and antigen retrieval method using citraconic anhydride was performed. Horseradish peroxidase (HRP) detection system (Biocare Medical \#MC541) was used and followed by $30 \mathrm{~min}$ incubation and chromogen DAB (DAB enhancer [5 min]; GBI Labs \# C07-25) application. Control sections were prepared using canine or feline lymph node. The neoplastic cells were strongly diffusely immunoreactive to PAX5, but not to CD3 (Fig. 4). Large numbers of immunoreactive mature non-neoplastic lymphocytes were admixed with the neoplastic cell population. The immunohistochemistry results were definitively consistent with TCRBCL.

In addition, PCR to detect antigen receptor rearrangements with primers for conserved regions of the $\mathrm{V}$ and $\mathrm{J}$ genes was performed. Briefly, the DNA extraction from archival cytological slides was performed using a commercially available kit (QIAamp DNA mini kit, Qiagen, GmbH, Germany) and amplification of immunoglobulin and T-cell receptor gamma sequences was performed using previously described primers [2]. Approximately 50-100 $n g$ of DNA was amplified with $500 \mathrm{~nm}$ of each primer in a $20 \mu \mathrm{l}$ reaction volume using $1 \times$ DNA Hot Start PCR Premix (LeGene biosciences, San Diego, CA, U.S.A.). PCR products were separated on $12 \%$ polyacrylamide gel (1.5 mm thick) by electrophoresis using $1 \times$ Tris borate EDTA buffer at $100 \mathrm{~V}$ for $90 \mathrm{~min}$. Result for PCR to detect antigen receptor rearrangements presented the pattern that $\mathrm{IgH}$ major primers which are specific for the majority of immunoglobulin gene rearrangements were strongly amplified, whereas the IgH minor primers which are specific for a smaller proportion of immunoglobulin rearrangements were weakly amplified suggesting B-cell malignancy (Fig. 5).

Subsequent to the fine needle aspiration and biopsy results, bone marrow examination was further intended for the staging of the lymphoma, but was denied by the owner due to economical constraint and demand for a therapy. Originally, no abnormal cells were identified in the peripheral blood smears. A standard 6 month CHOP chemotherapy protocol (modified Wisconsin) for treatment of lymphoma [10] was constituted. Briefly, the treatment was composed of vincristine $\left(0.7 \mathrm{mg} / \mathrm{m}^{2}, \mathrm{IV}\right), \mathrm{L}$ - asparaginase (400 U/kg, SC) 


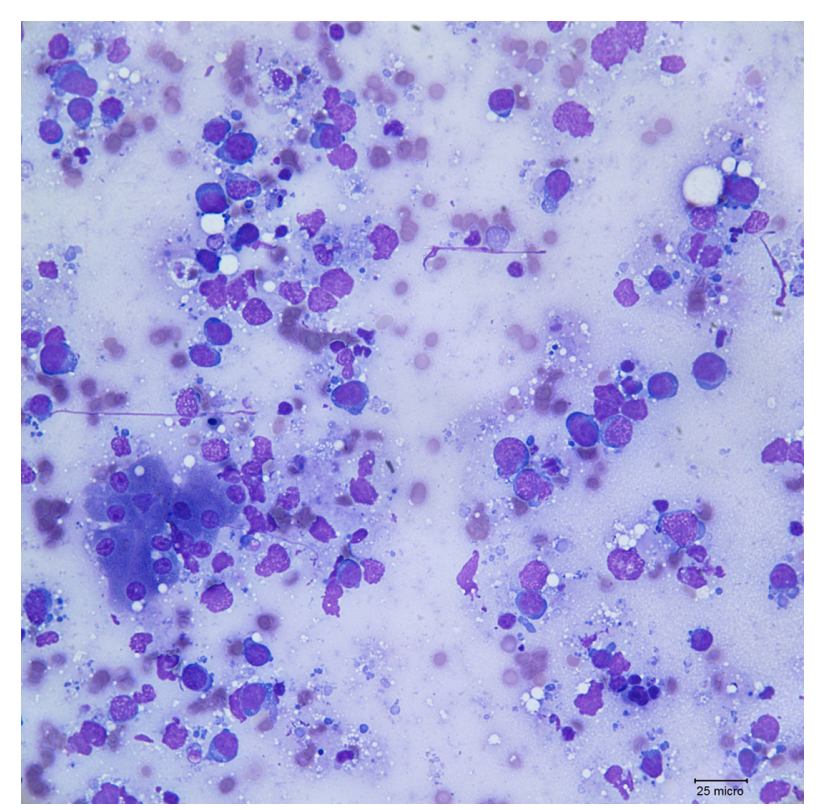

Fig. 2. Cytology of the liver hypoechoic lesion. Small clusters of hepatocytes with increased cytoplasmic basophilia, increased number of medium to large lymphocytes and a few disrupted cells were noted along with cellular debris and numerous cytoplasmic fragments. Wright-Giemsa, $\times 400$.

and prednisone (2 mg/kg, PO, SID) for 7 days in the first week, cyclophosphamide $\left(250 \mathrm{mg} / \mathrm{m}^{2}, \mathrm{PO}\right)$ and prednisone $(1.5 \mathrm{mg} / \mathrm{kg}, \mathrm{PO}, \mathrm{SID})$ for 7 days in the second week, vincristine $\left(0.7 \mathrm{mg} / \mathrm{m}^{2}, \mathrm{IV}\right)$ and prednisone $(1 \mathrm{mg} / \mathrm{kg}, \mathrm{PO}, \mathrm{SID})$ for 7 days in the third week and doxorubicin $\left(30 \mathrm{mg} / \mathrm{m}^{2}, \mathrm{IV}\right)$ and prednisone $(0.5 \mathrm{mg} / \mathrm{kg}, \mathrm{PO}, \mathrm{SID})$ for 7 days in the fourth week. However, despite the continued chemotherapy, even a partial remission was not achieved until after treatment with doxorubicin hydrochloride during week 4. On day 16 after initiation of chemotherapy, the patient was referred for respiratory distress. On an ultrasound examination, focal multiple round nodules were shown in liver parenchyma and renal cortex, unlike at two months ago. Focal lesions are seen in ultrasound images of the liver as small round nodules with a hypoechoic rim and a hyperechoic or isoechoic center. In addition, on post-contrast CT examination, hypodense multiple nodules were seen in bilateral renal cortex, which was suspected as infiltrative. There were no remarkable findings in cardiovascular and respiratory systems (Fig. 6). Complete blood count $(\mathrm{CBC})$ parameters were in normal, but the serumbiochemistry results showed significantly elevated BUN, creatinin, ALT and AST values than the reference range, indicating the liver and renal dysfunction. During the hospitalization, the patient was given fluid therapy using $0.459 \% \mathrm{NaCl}$ against dehydration and liver supporting medication including UDCA (30 mg/kg/day). The patient's condition continued to rapidly deteriorate clinically on day 23 of the chemotherapy protocol. The dog became more lethargic and developed hemoptysis and breathing difficulties on day 28 of chemotherapy and died. The autopsy was not

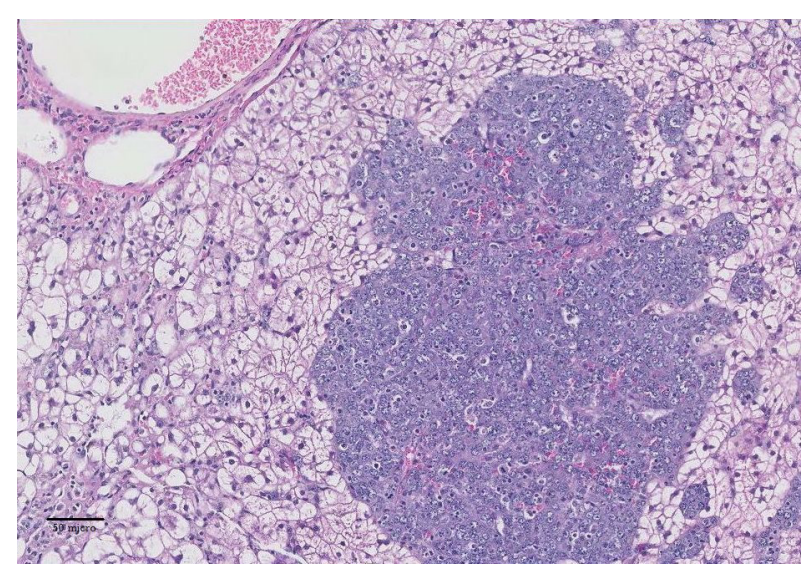

Fig. 3. Histologic section of surgical biopsy specimen from the liver in a dog. Note the cluster of large neoplastic cells within the adjacent hepatic parenchyma. Small numbers of mature lymphocytes were multifocally admixed with the neoplastic cell population. H\&E.

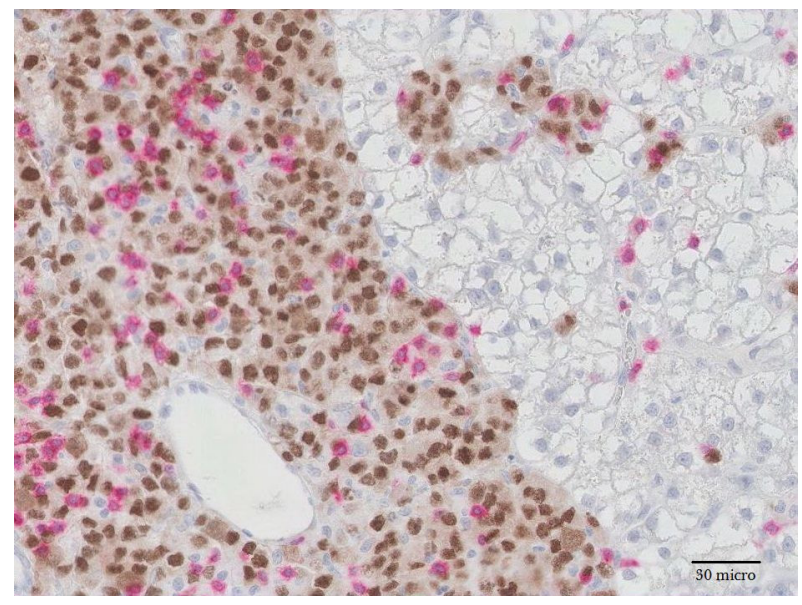

Fig. 4. Immunohistochemical section of the liver biopsy. Neoplastic cells are diffusely immunoreactive for PAX5 (brown). Large numbers of non-neoplastic mature lymphocytes are immunoreactive for CD3 (red).

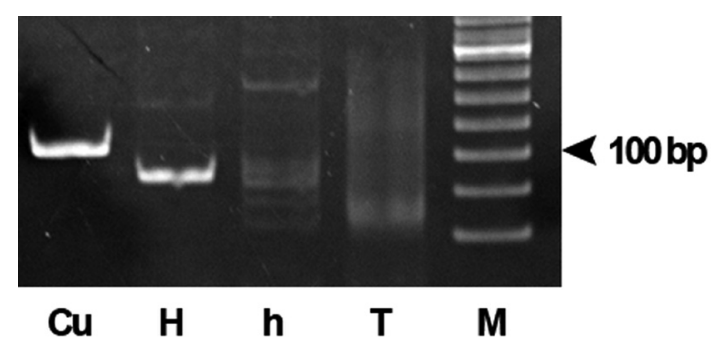

Fig. 5. Result of PCR to detect antigen receptor rearrangements from this case. Amplicons were loaded on $12 \%$ polyacrylamide gel for electrophoresis. PCR was performed using primers for the positive DNA control, $\mathrm{C} \mu$ (lane $\mathrm{C}$ ), Ig $\mathrm{H}$ major (lane $\mathrm{H}$ ), Ig $\mathrm{H}$ minor (lane h) and TCR $\gamma$ (lane T). Lane M refers a DNA size marker. 


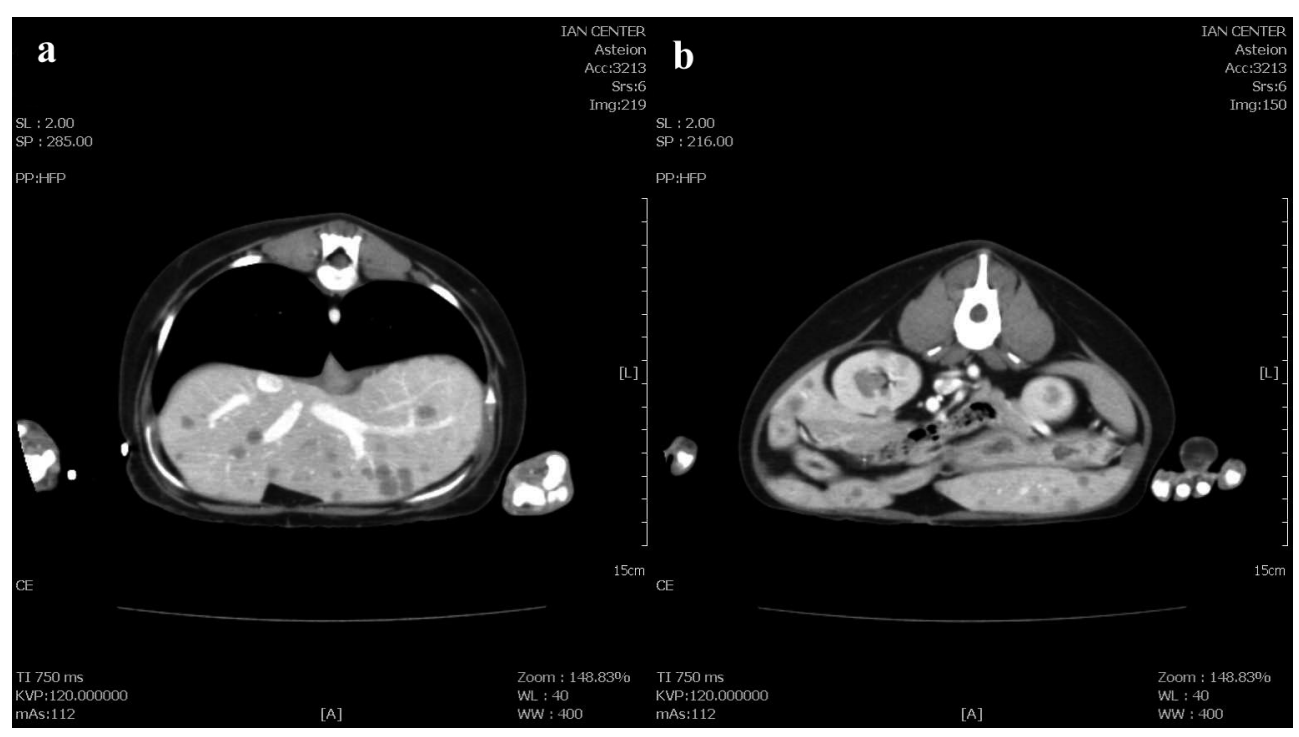

Fig. 6. Post-contrast CT image shows that multiple round hypodense nodules located generally in liver parenchymal and renal cortex.

performed, since the owner was unacceptable to do it.

TCRBCL is a histologic variant of the diffuse B-cell lymphoma group, which has been reported only in the other animal species than dogs with middle aged individuals. Multicentric TCRBCL with a mixed cell population of large to small round cells has been reported in a pig, and the neoplastic tissue findings were similar to those of human TCRBCL [12]. TCRBCL has been described in an older cat with the same morphologic preferences as human TCRBCL $[3,11]$. Only one study has reported orbital TCRBCL in an 11-year-old Shetland sheepdog [1]. However, there are no reports involving very young dogs (7 months old) with lymphoma primarily affecting the liver and no response to chemotherapy. The case presented here suggests that juvenile dogs can also develop TCRBCL.

In the present case, initial biopsies of the hepatic mass had characteristics consistent with descriptions of TCRBCL in both the human and veterinary literatures. The histologic analysis of the affected tissues revealed a diffuse predominant population of small nonneoplastic lymphoid cells with fewer large neoplastic lymphoid cells. These large neoplastic cells were morphologically suggestive of immunoblastic B lymphocytes. They were CD3 negative, and the scattered cells $(5 \%)$ were PAX5 positive on immunostaining. All of the neoplastic cells had similar morphology as that of human TCRBCL. The majority of the background population was composed of CD3-positive small T lymphocytes. Occasional large round to oval neoplastic cells were present in the background. Mitotic figures were seen in the population of large cells only. These large cells were PAX5 positive on immunostaining. Nearly all of the small lymphoid cells were CD3 positive with only a few scattered small background lymphocytes being PAX5 positive. These findings suggest that lymphomagenesis in this case was contributed by PAX5 overexpression, which significantly reduced p53 gene expression, which is normally regulated by PAX5. PAX5 (B-cell-specific activator protein, BSAP) is a member of the paired box domain gene family that encodes nuclear transcription factors important in development, differentiation, cell migration and proliferation [4]. PAX5 protein is expressed as a nuclear marker in B-lineage cells that span the differentiation spectrum from precursor B cells to early plasma cells [7].

A rapid response to chemotherapy is consistent with the reported chemoresponsive nature of TCRBCL in humans [9] and of lymphoma in dogs [8]. Case reports in humans have documented remission following early aggressive chemotherapy. Data regarding the biologic behavior, clinical response and outcome of TCRBCL in veterinary medicine are still limited. However, hepatic TCRBCL in a juvenile dog with no response to aggressive chemotherapy has not been reported previously in dogs. Previous reports indicate that lymphoma is slowly progressive and typically affects older animals. However, our case suggests that a positive prognosis should not be expected in hepatic TCRBCL despite aggressive chemotherapy (CHOP protocol), if the patient is too young at the age of onset. In addition, more population studies on juvenile TCRBCL cases need to analyze the molecular pathogenesis of juvenile TCRBCL.

Early recognition and diagnosis are important for clinical management and good outcomes. Although extremely rare, hepatic TCRBCL should be included in differential diagnoses even when young dogs present with acute hepatopathy. The prognosis of TCRBCL is dependent on starting aggressive chemotherapy immediately. In general, older individuals report a good prognosis with the CHOP chemotherapy protocol in the veterinary literature. However, the present case was hepatic TCRBCL in a juvenile dog with a poor prognosis. This is the first description of hepatic TCRBCL in a juvenile dog. We hope more case reports and reviews 
of hepatic TCRBCL in juvenile dogs will provide oncologic information for veterinary clinical practitioners and oncologists and will be useful in further research and clinical trials.

ACKNOWLEDGMENT. This work was carried out with the support of "Cooperative Research Program for Agriculture Science \& Technology Development (Project title: Development of insect-based aquaculture feed ingredient, Project No: PJ01003402)" Rural Development Administration, Republic of Korea.

\section{REFERENCES}

1. Aquino, S. M., Hamor, R., Valli, V., Kitchell, B., Tunev, S., Bailey, K. and Ehrhart, E. 2000. Progression of an orbital T-cell rich B-cell lymphoma to a B-cell lymphoma in a dog. Vet. Pathol. 37: 465-469. [Medline] [CrossRef]

2. Burnett, R. C., Vernau, W., Modiano, J., Olver, C., Moore, P. and Avery, A. 2003. Diagnosis of canine lymphoid neoplasia using clonal rearrangements of antigen receptor genes. Vet. Pathol. 40: 32-41. [Medline] [CrossRef]

3. Day, M. J., Kyaw-Tanner, M., Silkstone, M., Lucke, V. and Robinson, W. 1999. T-cell-rich B-cell lymphoma in the cat. J. Comp. Pathol. 120: 155-167. [Medline] [CrossRef]

4. Desouki, M. M., Post, G. R., Cherry, D. and Lazarchick, J. 2010. PAX-5: a valuable immunohistochemical marker in the differential diagnosis of lymphoid neoplasms. Clin. Med. Res. 8: 84-88. [Medline] [CrossRef]

5. Ettinger, S. N. 2003. Principles of treatment for canine lymphoma. Clin. Tech. Small Anim. Pract. 18: 92-97. [Medline] [CrossRef]
6. Fry, M. M., Vernau, W., Pesavento, P., Brömel, C. and Moore, P. 2003. Hepatosplenic lymphoma in a dog. Vet. Pathol. 40: 556-562. [Medline] [CrossRef]

7. Jensen, K. C., Higgins, J. P., Montgomery, K., Kaygusuz, G., van de Rijn, M. and Natkunam, Y. 2007. The utility of PAX5 immunohistochemistry in the diagnosis of undifferentiated malignant neoplasms. Mod. Pathol. 20: 871-877. [Medline] [CrossRef]

8. Mutsaers, A. J., Glickman, N. W., DeNicola, D. B., Widmer, W. R., Bonney, P. L., Hahn, K. A. and Knapp, D. W. 2002. Evaluation of treatment with doxorubicin and piroxicam or doxorubicin alone for multicentric lymphoma in dogs. J. Am. Vet. Med. Assoc. 220: 1813-1817. [Medline] [CrossRef]

9. Pfreundschuh, M., Trümper, L., Österborg, A., Pettengell, R., Trneny, M., Imrie, K., Ma, D., Gill, D., Walewski, J. and Zinzani, P. L. 2006. CHOP-like chemotherapy plus rituximab versus CHOP-like chemotherapy alone in young patients with good-prognosis diffuse large-B-cell lymphoma: a randomised controlled trial by the MabThera International Trial (MInT) Group. Lancet Oncol. 7: 379-391. [Medline] [CrossRef]

10. Rassnick, K. M., McEntee, M. C., Erb, H. N., Burke, B. P., Balkman, C. E., Flory, A. B., Kiselow, M. A., Autio, K. and Gieger, T. L. 2007. Comparison of 3 protocols for treatment after induction of remission in dogs with lymphoma. J. Vet. Intern. Med. 21: 1364-1373. [Medline] [CrossRef]

11. Steele, K. E., Saunders, G. and Coleman, G. 1997. T-cell-rich B-cell lymphoma in a cat. Vet. Pathol. 34: 47-49. [Medline] [CrossRef]

12. Tanimoto, T. and Ohtsuki, Y. 1998. T-cell-rich B-cell lymphoma in a pig. Vet. Pathol. 35: 147-149. [Medline] [CrossRef]

13. Valli, V. E., Vernau, W., de Lorimier, L. P., Graham, P. and Moore, P. 2006. Canine indolent nodular lymphoma. Vet. Pathol. 43: 241-256. [Medline] [CrossRef] 